\title{
TECNOLOGÍA EN INFORMÁTICA
}

\begin{tabular}{|c|c|c|}
\hline Estudiante & Proyecto & Asesor \\
\hline $\begin{array}{l}\text { Castro Pedraza } \\
\text { Camilo Andrés }\end{array}$ & $\begin{array}{l}\text { Sistema de información para el segui- } \\
\text { miento de ingresos y gastos de un ve- } \\
\text { hículo de servicio publico. }\end{array}$ & $\begin{array}{l}\text { Jose Ovidio } \\
\text { Salamanca López }\end{array}$ \\
\hline $\begin{array}{l}\text { Torres Córdoba } \\
\text { Johana Patricia }\end{array}$ & $\begin{array}{l}\text { Sistemas de gestión para la elabora- } \\
\text { ción de certificados al proveedor. }\end{array}$ & $\begin{array}{l}\text { Jose Ovidio } \\
\text { Salamanca López }\end{array}$ \\
\hline $\begin{array}{l}\text { Guacaneme } \\
\text { Álvaro Eric Geovany }\end{array}$ & $\begin{array}{l}\text { Sistema de información para la ad- } \\
\text { ministración de inventarios y de infor- } \\
\text { mación para la empresa cultura vital } \\
\text { producciones. }\end{array}$ & $\begin{array}{l}\text { Helio Henry } \\
\text { Ramírez Arévalo }\end{array}$ \\
\hline $\begin{array}{l}\text { Valbuena Calderón } \\
\text { Leonardo }\end{array}$ & $\begin{array}{l}\text { Herramientas didáctica para el apren- } \\
\text { dizaje y refuerzo de la conjugación de } \\
\text { verbos de la lengua francofona a tra- } \\
\text { vés de un web services en java. }\end{array}$ & $\begin{array}{l}\text { Luis Eduardo } \\
\text { Pérez Peregrino }\end{array}$ \\
\hline $\begin{array}{l}\text { - Sierra Sierra } \\
\text { William Dairo, } \\
\text {-Angarita Tavera } \\
\text { Jorge Luis }\end{array}$ & $\begin{array}{l}\text { Sistema de información estudiantil } \\
\text { software educativo. }\end{array}$ & $\begin{array}{l}\text { Luis Eduardo } \\
\text { Pérez Peregrino }\end{array}$ \\
\hline Parada Niño Julián & $\begin{array}{l}\text { Análisis y diseño de implantación } \\
\text { de historias clínicas de régimen } \\
\text { subsidiado. }\end{array}$ & $\begin{array}{l}\text { José Fernando } \\
\text { Pinto Cruz }\end{array}$ \\
\hline $\begin{array}{l}\text { Baracaldo González } \\
\text { Lady Katherine }\end{array}$ & $\begin{array}{l}\text { Sistemas de información de finca ga- } \\
\text { nadera "San Antonio". }\end{array}$ & $\begin{array}{l}\text { Carlos Armando } \\
\text { López Solano }\end{array}$ \\
\hline $\begin{array}{l}\text { Rivera Moreno } \\
\text { Mario Alexander }\end{array}$ & $\begin{array}{l}\text { Administración de artículos del consor- } \\
\text { cio serrezuela. }\end{array}$ & $\begin{array}{l}\text { Alejandro } \\
\text { Moreno Pinilla }\end{array}$ \\
\hline $\begin{array}{l}\text { - Miranda Campos } \\
\text { - Libardo Enrique }\end{array}$ & $\begin{array}{l}\text { Prototipo de registro y control de tran- } \\
\text { sacciones ganadería hr. }\end{array}$ & $\begin{array}{l}\text { Miguel } \\
\text { Hernández Bejarano }\end{array}$ \\
\hline $\begin{array}{l}\text { Arciniegas Plazas } \\
\text { Gustavo Adolfo }\end{array}$ & $\begin{array}{l}\text { Caracterización del programa de } \\
\text { Tecnología en Informática de Unimi- } \\
\text { nuto. }\end{array}$ & $\begin{array}{l}\text { Jhon Francined } \\
\text { Herrera Cubides }\end{array}$ \\
\hline $\begin{array}{l}\text { Eslava Vargas } \\
\text { Diana Carolina }\end{array}$ & $\begin{array}{l}\text { Caracterización estudiantil del pro- } \\
\text { grama de Tecnología en Informática } \\
\text { en el marco del proyecto de trans- } \\
\text { ferencia y apropiación del proyecto } \\
\text { Cupi2 A Uniminuto. }\end{array}$ & $\begin{array}{l}\text { Jhon Francined } \\
\text { Herrera Cubides }\end{array}$ \\
\hline $\begin{array}{l}\text { Mejia Sierra } \\
\text { Alba Carolina }\end{array}$ & $\begin{array}{l}\text { Caracterización de la población do- } \\
\text { cente en el marco de la transferen- } \\
\text { cia del proyecto Cupi2 A Uniminuto. }\end{array}$ & $\begin{array}{l}\text { Jhon Francined } \\
\text { Herrera Cubides }\end{array}$ \\
\hline
\end{tabular}

